Mcine Auffassung der Willensfreiheit. Wilhelm Stern, M.D. Berlin.-The speaker outlined the theory of freedom which is the groundwork of his treatise on positivistic ethics (Berlin, I897). The doctrine is a subjective determinism, based upon empirical psychology.

The Value of Hypotheses in Psychology. Professor E. F. BuchXER, New York.- - Recent psychology has been engaged in gathering data-facts in and about consciousness. There is now a tendency to begin a generous discussion of the concepts derived from them. This praiseworthy attitude will lead to a careful analysis of the explanatory hypotheses by the scientists themselves, rather than by the metaphysician solely. The assumption of mental processes, of faculties is. dynamic development, of psychical dispositions, of a simple relation between cerebral processes and conscious products-these hypotheses were discussed from a psychological point of view with reference to their adaptation to the phenomena of the science.

L'illusion du libre arbitre. Sully Prudhomare, Paris."Whether free acts exist or do not exist, man has the illusion, at least, if not the real assurance, that, according to the witness of his consciousness, such acts do exist in the exercise of his will. This is an entirely empirical statement on my part, and I am entirely astonished at it; for is it not surprising, if everything in the universe is necessitated, that a mental state should be found from which to represent non-necessity, even if it is an illusion? From what combination of necessary factors can come such an image, whether true or false, of something which implies absolutely nothing of necessity and even represents its opposite? There is here certainly a problem to be solved. I can only call attention to it."

UNIVERSITY OF IOWA.

C. E. Seashore.

\title{
IMITATION.
}

The Theory of Imitation in Sacial Psychology. Charles A. Eliwood. American Journal of Sociology, VI. (6). Pp. 721-741.

This paper, which was read before the meeting of the Western Philosophical Association last January, is a criticism of the position that imitation is the sole method of individual development and social organization. The author advances four arguments against such a position. First, the selection of models for imitation, the fact that we do not imitate all the copies presented, implies the existence of other 
instinctive factors beside imitation. Second, the theory makes too great a gulf between sub-human societies, organized on the basis of other instincts, and human society, which is supposed to be based on a single instinct, that of imitation. Third, it does not sufficiently recognize the importance of natural selection, in its psychical aspect, as a factor in human progress. And fourth, the theory 'rests upon no sufficient basis of ascertained facts.' It is, in short, too abstract, too far removed from the facts of life. "Both as M. Tarde and as Professor Baldwin conceive it, the social process is a process which might very well go on in a company of disembodied spirits-in a vacuum!"

There is no doubt that the author's general position is a safe one. One cannot read Tarde without becoming aware of the danger of supposing that the fact of repetition in society always indicates the process of imitation as its cause. But this pushing of the principle of imitation to its extreme limits is really an instance of the method that must be pursued in dealing with a new or a neglected factor. In order to find out what it will explain, we must proceed on the hypothesis that it will explain everything. It is well when the exploiter of a principle can also be its critic, but sometimes the constructive part of his work gains in enthusiasn and thoroughness if he leaves the limiting and paring-down process to others.

CORNEII UNIVERSITY.

Margaret Floy Washburn.

\section{PSYCHICAL RESEARCH.}

Proceedings of the Society for Psychical Research. Parts 36-40;

Vol. XV. Feb., rgoo, to Feb., I9or. Pp. 522.

Of these five parts, three (Nos. 37,39 and 40 ) contain reports upon the meetings of the Society, Mr. Myers' presidential address and an address in memory of Professor Sidgwick. The articles calling for more extended notice are found chiefly in Parts $3^{6}$ and $3^{8}$, with one in 40.

Part 36 contains four leading articles. 'The Fire Walk' and 'Reflections on Mrs. Piper and Telepathy,' by Andrew Lang; 'Discussion of the Trance Phenomena of Mrs. Piper,' by Mrs. Sidgwick; - On some Philosophic Assumptions in the Investigation of the Problem of a Future Life,' by F. C. S. Schiller.

Mr. Lang reports three recent, and some earlier, descriptions of the 'Fire Walk.' In the first of the three, Col. Gudgeon, British 